biotic therapy in Proteus mirabilis pyelonephritis, Streptococcus agalactae infections, and chemoprophylaxis of induced typhoid fever and tularæmia.

Papers summarizing and discussing problems in methodology included: preparation and performance of antibiotic disks as aids in determining antibiotic sensitivity of bacteria; the occurrence of antibiotic-producing actinomycetes in soils, X-ray powder difffraction in identification of antibiotics, and preparative thin-layer chromatographic methods as used in investigations of antibiotics. The anticoagulant properties of tetracyclines and complexes formed between tetracyclines and penicillins with blood serum proteins were also discussed.

The programme included 174 presented papers, 17 papers as "read by title", and 2 papers listed but not presented. Most of these 193 papers will appear in Antimicrobial Agents and Chemotherapy-1963, which will be published by the American Society for Mierobiology later in 1964. This will be distributed to all registrants at the meeting (as a result of a combined fee for registration and the book) and will be available for 12 dollars from the American Society for Microbiology. The papers were contributed by laboratories in Canada, Chile, Czechoslovakia, Greece, Japan, Puerto Rico, West Germany, as well as the United States.
Exhibits were included as part of the meeting for the first time with 18 firms represented. These stressed equipment used in growing antibiotic-producing microorganisms, methods of assaying antibioties, various types of laboratory glassware, tissue culture media ingredients, equipment used in chemical laboratories including tracer techniques, bacteriological equipment, etc.

Plans for the fourth Interscience Conference on Antimicrobial Agents and Chemotherapy are already under way. This meeting will be held during October 26-28, 1964, in the Commodore Hotel, New York City. The programme committee under the chairmanship of Nestor Bohonos has already begun organizing this meeting. Their plans will take into account the results of a public opinion poll held at the third Conference. The majority of the 197 registrants responding favoured a three-day meeting with as many as three simultaneous sessions instead of a four-day meeting (with double sessions), symposia but not contributed papers in the evening (if evening sessions are necessary), and having exhibits. The deadline for abstracts of contributed papers is July 24, 1964. Further information can be obtained from the office of the executive secretary of the American Society for Microbiology, R. W. Sarber, 115 Huron View Boule. vard, Ann Arbor, Michigan.
David Perlman

\title{
ITERATIVE SOLUTION OF LINEAR EQUATIONS
}

A SEMTNAR on "Iterative Solution of Linear Equations" was held at the National Physical Laboratory, Teddington, during September 25-27, 1963. More than a hundred visitors from industry, universities, technical college research departments, and Government service participated in the programme of eight lectures on fundamental theory, four shorter contributions on the effective use of computer's in practical problems, and informal discussion periods.

During the past fifteen years an immense amount of research has been undertaken on iterative methods for solving large sets of linear algebraic equations-principally in response to the needs of nuclear engineering-and concepts are now available whereby the main results can be related conveniently to each other. An elegant textbook on the subject, ty Prof. R. S. Varga of the Case Institute of Technology, Ohio, had been published (Matrix Iterative Analysis, Prentice-Hall, London, 1963), and it was appropriate to signal its appearance by a meeting which would present a survey of recent work to persons directly concerned with the subject in Britain. Such was the purpose of the seminar organized by the Mathematics Division of the National Physical Laboratory as part of its programme to promote the exchange of information on computer applications.

The participants assembled after lunch on September 25 and were welcomed by the deputy director of the Laboratory, Dr. J. V. Dunworth. Dr. M. S. Lynn of the National Physical Laboratory then spoke on "Basic Concepts of the Theory of Iterative Methods". His talk covered the matrix definition of point and block over-relaxation and the dependence of over-relaxation theory on the classieal Jacobi and Gauss-Seidel methods; the distinction between asymptotic and average rates of convergence; the basic Perron-Frobenius theorems for non-negative matrices; the properties of matrices which are cyclic of index $k$; and the Stein-Rosenberg and Ostrowski-Reich theorems and their corollaries applicable to irreducible $M$-matrices.

The other paper of the afternoon was "Discretization of Elliptic and Parabolic Partial Differential Equations Consistent with Iterative Theory" by A. R. Curtis of the Atomic Energy Research Establishment, Harwell. Discussed here was the general parabolic boundary problem in one space variable with interfaces, and its discretization by the integration method to provide an irreducible $M$-matrix, the Jacobi matrix of which has many of the properties described by Dr. Lynn. (The Taylor expansion and the variational methods of discretization were seen to be less satisfactory in this respect.) The self-adjoint problem in more than one space variable was shown also to lead to a real, symmetric matrix to which a large number of theoretical results are applicable.

The lectures of the following day began with "The Theory of Succossivo Over-relaxation", by Dr. Joan Walsh of the University of Manchester. Young's Property $A$ and consistent ordering were defined; the form and eigenvalues of the iteration matrix, and an expression for the over-relaxation parameter were given for eyclic matrices of index $k$; and these results were extended to block relaxation.

Dr. H. E. Wrigley of tho Atomic Energy Research Establishment, Winfrith, followed with "Chebyshev Accelerated Methods". The relevance of Chebyshev polynomials was demonstrated, and for cyclic Hermitian matrices of order 2 and for non-cyclic matrices the convergence rates of the associated iterative methods were compared with those of over-relaxation. The case of non-Hermitian matrices was examined and definitions of optimum convergence presented, but the effectiveness of the acceleration technique was shown to depend critically on the information available on the eigenvalue distribution.

The first afternoon lecture was "The Estimation of Relaxation Parameters in Successive Over-relaxation", by B. A. Carré of the University of Southampton. The optimum parameter depends eritically on the spectral radius of the Jacobi matrix, and methods of determining this quantity accurately were compared in detail. Special attention was directed to Neumann problems: these are often troublesome, but little information has been published about them.

D. E. Jones of the Meteorological Office, Bracknell, then described "Alternating Direction Implicit Methods", which have been highly successful with the self-adjoint reactor flux equation. The matrix is separated into two components, each of which is similar to a tridiagonal Stieltje's matrix; and when these components commute, a number of theorems guarantee the convergence of the 
iteration. Optimum relaxation parameters are determined by minimax results for a rational function of the eigenvalues of the matrix components.

On the last morning, under the title "Further Concepts of Iterative Theory and Practice", Dr. Lynn of the National Physical Laboratory discussed quantitative criteria for terminating an iteration automatically, and the organization of block over-relaxation on magnetic tape. Mr. S. Michaelson of the University of Edinburgh spoke on "Choice of Methods in Adverse Problems" and directed attention to the merits of the Bickley-McNamee method and the Schwarz technique for treating problems in L-shaped regions. He also described his experience in solving free-boundary problems in lubrication investigations.
In the afternoon, A. R. Crump of the Nuclear Power Group, Knutsford; Dr. J. C. W. Corcoran of the English Electric Co., Stafford; Dr. R. J. Allwood of English Electric-Leo Computers, Kidsgrove, and J. H. MeDonnell of English Electric Aviation, Warton, deseribed respectively problems arising in the fields of reactor development. electrical network analysis, the analysis of frameworks in civil engineering, and in aeronautical structures. The meeting concluded with a general discussion.

Copies of the pre-circulated notes for the first six lectures are still available, and may be obtained from Dr. D. W. Martin, Mathematies Division, National Physical Laboratory, Teddington, Middlesex, under reference $M a 44 / 027$.

D. W. Martin

\section{A POLICY FOR DEVELOPMENT AND GROWTH IN SCOTLAND}

\begin{abstract}
A BROADSHEET entitled A Development Plan for Scotland*, which was written for Political and Economic Planning by G. McRobie, anticipated by about a month the Government's own proposals outlined in the White Paper, Central Scotland-a Programme for Developmint and Growth (H.M.S.O. Cmnd. 2188). Its concise summary of the findings of earlier investigations, such as tho Toothill Inquiry into the Scottish Economy (1961) and that of the National Economic Development Council, Conditions Favourable to Faster Growth, assists the objoctive discussion of the Government's plans. It illustrates the fact that effective regional planning requires decisions about the distribution of populations and investment in basic industries and services which are essentially national in character. It emphasizes, secondly, the fact that within Scotland there are problems of congestion and drift of population, and also needs and resources, which are specific to Scotland, calling for action in harmony with its people and resources, that is, for Scottish decisions. For Britain, it insists, probably more than for any other industrial nation. recent trends in the growth and movement of population have made a comprehensive poliey for regional development a national necossity. The approach and measures suggested in the Broadsheet are, in principle, applicable equally to other parts of Britain.
\end{abstract}

For Scotland, it is suggested that the objective should be to maintain roughly the existing proportion of Britain's population. With a fully employed population this would require a net increase of 150,000 jobs in Scotland over the next six years, of which 100.000 must be created by the expansion of manufacturing industry. With this a policy on distribution of employment and population must be developed, including an acceptable internal structure and a better environment. It is proposed that the whole of Scotland should be treated as a development district, with widely representative District Councils to assess the needs and resources of their districts, set targets for employment and trade, and marshal public opinion in support of district development plans. This need not await the creation of a strong central planning authority covering the whole of Scotland; however, it could help to promote one and supply the information on local needs and resources, local units of administration that the central authority would need, besides an informed and sympathetic body of public opinion, if it is to be effective.

No plans for Scotland can come to anything, however, unless the Scottish economy has an adequate basis in fuel and transport. and at present national policies are not geared to the potential expansion of economic activity in Scotland, which, to attain the objectives visualized in

* Planning, 29, No. 476 (October 14, 1963). A Development Plan for Scotland. Pp. 399-434. (London: Political and Economic Planning, 1963.) 4s. $6 d$. the Broadsheet, must expand at about 5 per cent a year for the next seven or eight years. For transport this means no curtailment of facilities must be permitted until the needs of all localities have been assessed in the light of targets for employment and trade. A. Scottish fuel policy must also be based on a long-term view of require. ments and supplies of energy. It must recognize that by the 1980's Scotland is likely to need energy equivalent to more than 40 million tons of coal, a rapidly growing proportion of which will be in the form of electricity. Decisions as to whether the power stations which will have to be built in the later 1970's are to be coal-or oil-fired cannot long be delayed if Scottish coal resources are to be utilized to the greatest national advantage. The Broadsheet suggests that for a firm basis of future power requirements, Scottish fuel policy should aim at an output of 20-25 million tons of coal annually by the early 1980's.

The Government's development proposals, as the title of the White Paper indicates, are limited to Central Scotland. They comprise an increased annual public service investment programme of $£ 140$ million in which roads and bridges form an important part, and in considering the Beeching proposals for railway closures the Minister of Transport will take account of the present and prospective consequences for the area involved. Three new power stations are to be built, and besides an expanded housing programme, more monoy will bo spent in an attack on squalor and decay in industrial areas, as a prelude to extensive new growth. In the GrangemouthFalkirk area, the Universities of Glasgow and Edinburgh will assist in preparing a comprehensive schome for economic and physical expansion to increase the population by 55,000. The now University of Strathclyde and other developments envisaged by the Robbins Committee are seen as providing a powerful framework for higher technological education and research. The Scottish Development Group will be responsible for phasing and co-ordinating the programme for Central Scotland and extending its surveys to other parts of Scotland, and the Government is prepared to make a financial contribution to the Scottish Council for its work in publicizing Scotland.

Very little was added from the Government sido when the White Paper was debated in the House of Commons on December 3 and 4. Mr. E. Heath, the Secretary of State for Industry, 'Trade and Regional Development and President of the Board of Trade, said that investigations of population and economic prospects over tho next twenty years were already in hand for parts of Scotland outside the central zone, and he had set up an interdepartmental group under Board of Trade chairmanship to survey economic and planning problems in the northwest, which would start from the investigations of landuse on Merseyside and the Manchester conurbation undertaken by the Ministry of Housing and Local Government. The Secretary of State for Scotland, Mr. 